FIU DE FEIRA

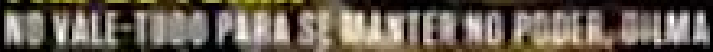

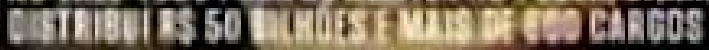

A ERIPE QUE MATA

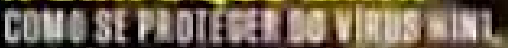

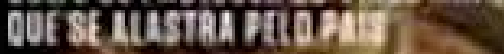

国

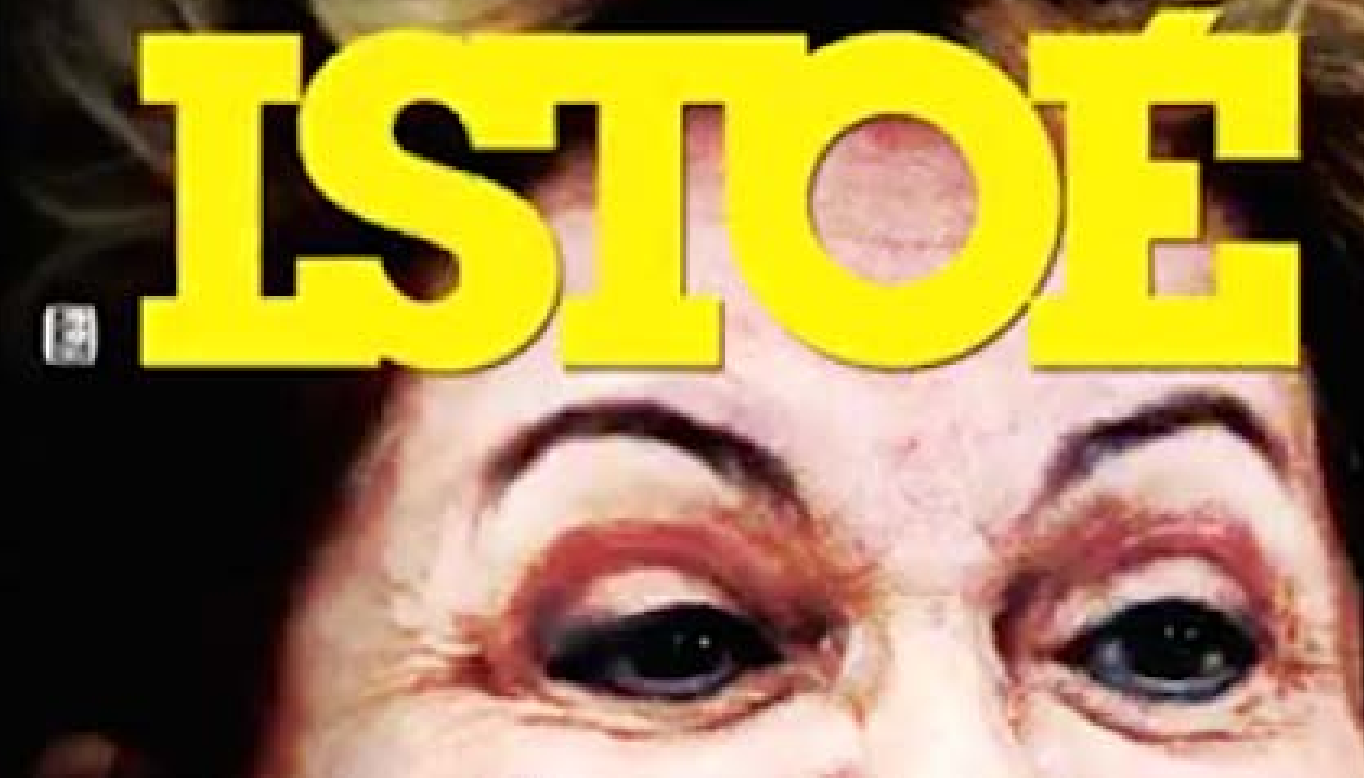

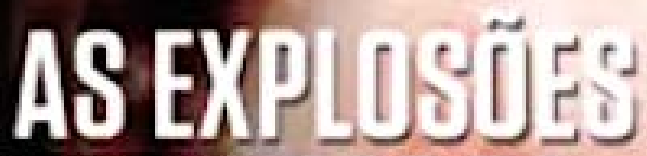
NERIDS! S D! PRESID EN]D

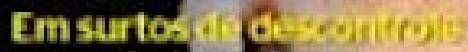
coma Imine of de seu afastananito completamente fora of st, Dilma quebra movets: dentro do Palles, gith comstoordinad of, xinga autoridades, ataca poderes constituidos eperde (tambatin) as condlçoes emocionas para condurar o pals 


\title{
A VIDA PÚBLICA DE UMA MULHER
}

\section{Cristina Thorstenberg Ribas}

\author{
esfera pública macropolítica \\ democracia minoria
}

\begin{abstract}
As mulheres se tornaram uma grande força de expressão no ciclo de lutas em defesa da democracia nos últimos anos no Brasil. Neste texto analiso como a luta das muIheres passa também por sua insistência no direito a ter uma vida pública e como a proliferação de modos de expressão é uma das forças dessa luta.
\end{abstract}

\begin{abstract}
A WOMAN'S PUBLIC LIFE | In the recent years in Brazil women have become a great force of expression in the cycle of struggles in the defense of democracy. In this text I analyze how the women's struggle for their lives also goes through their insistence on the right to have a public life and how the proliferation of modes of expression is one of the forces of this struggle. | Public sphere, macropolitics, democracy, minority.
\end{abstract}

\section{Pré-texto}

Este texto foi escrito entre 2014 e 2016 e se atualiza com este pré-texto em 2018. A vida pública de uma mulher é aqui o pré-texto da vida de muitas mulheres, de muitas mulheres de cor, negras, indígenas, pobres, classe média, sem classe, mulheres trans, mulheres cruzando gênero. Lésbicas, aborteiras, cafetinas, prostitutas. Somos muitas. "Mexeu com uma mexeu com todas." 2018, a vida pública de uma mulher é interrompida pelo patriarcado corrupto. Assassinato de Marielle Franco. Mulheres silenciadas, perdendo direitos e perdendo o direito à vida pública. Não toleramos. Neste texto eu pergunto, como mulher militante, como resistir na defesa da democracia de direito (o significante comum "luta pela democracia") sem achatar a singularidade das lutas que já se faziam públicas a partir do ciclo de 2013? Que novas formas de luta e subjetividades políticas emergiram nesses anos? Que expressões políticas, estéticas, animistas, radicais essas lutas produzem? Não são esses modos de existência já expressões estéticas? E por isso mesmo corpos e vidas que destituem a incisão do poder neofascista? Nestes anos nós mulheres viemos explodindo as determinações que apartam e alienam nossas individualidades apostando em formas coletivas, em que o subjetivo e o político fazem parte da mesma matéria, o subjetivo e o objetivo da vida e das lutas. Teorias feministas ${ }^{1}$ e cartografias esquizoanalíticas ${ }^{2}$ são aliados na constituição desse saber-corpo, desses modos de expressão em forma de "cartografias mutantes", ${ }^{3}$ confundindo estrategicamente o "performar"4 gênero, produzindo a si, em subjetivações coletivas. Este pré-texto é um convite a entrar numa certa vibração: ler 
este texto com a sapiência de que o corpo que luta não teme. O corpo ginga, compõe e dança, sem cessar: "pisa ligeiro pisa ligeiro, quem não pode com as mulheres não atiça o formigueiro" - como o canto de várias etnias indígenas.

\section{Ressalva}

O perigo em que incorro neste texto, na afirmação de um genérico conceito de "mulher" (e ou nas variações que vou abrindo), é parte do espaço para que outras vozes respondam - outros corpos e outras singularidades em seus vir a ser mulher e em devires-mulher.

\section{Texto}

O Brasil passa por um momento em que binarismos estão sendo rasgados, a torto e a direito. O crescimento de mídias sociais, uma produção semiótica incontrolável e a tomada das ruas desde 2013 produzem um contraste com as capas dos jornais das grandes mídias que repetem formas e headlines de 30 anos atrás. Aqueles que, como eu, nasceram ao final da ditadura de estado e se politizaram, precoces, no \#ForaCollor, estão/estamos tendo a chance de viver o peso do que foram os anos de chumbo, ainda que práticas implementadas na ditadura nunca tenham desaparecido das periferias do Brasil. $^{5}$

A vida das brasileiras e dos brasileiros induzidos ao binarismo do pró ou contra o golpe é atravessada por uma diversidade de discursos: são as minorias que multiplicam os pontos do debate, minorias achatadas pelas porções que se comportam de maneira majoritária. O bloco "de oposição" que tem tirado (ou já tirou) Dilma Roussef do poder enseja destruir direitos básicos constitucionais e muitos direitos adquiridos nos anos de governo liderados por Lula e Dilma. O primeiro impacto desse embate, contudo, tem-se dado diretamente contra as lutas das mulheres, contra as lutas das minorias e, recentemente, pela repressão aos movimentos que demandam o cumprimento da democracia como direito. A luta por direitos e espaços comuns para além de uma "vida pública" está num embate encurralado contra vidas privadas - vidas ainda mais voluntariamente entrelaçadas com o capital e seus modos de semiotização. Mas por outro lado, nada de novo. Aquele espaço transversal de relação entre a sociedade e o poder representado já vinha sendo anulado no governo do PT e seus aliados, antes mesmo do "golpe". Sem falar do esgotamento da forma-partido, exposto pelas alianças que se produziram há anos de maneira a tornar primeiro elegível e depois governável uma coalizão. Dilma - primeira mulher eleita presidenta, foi afastada do poder por aqueles que agora se tornaram, do ponto de vista dos que sofreram o golpe, "traidores". Avaliando o balanço do "pró-impeachment" e "contra o golpe" o que é, de fato, que precisamos defender agora? Por onde se movem as lutas? De onde extraem sua força? Que formas de expressão elas geram?

Em meio ao binarismo pró ou contra o golpe, a "democracia" virou um sujeito, e por que não? melhor, uma sujeita - sujeita ao seu reclame, à pauta em geral de uma sociedade que precisava rever o que se passava no Planalto Central, que precisava colocar nas vias de fato as transversais que conectam (ou não) os cidadãos a seu governo, precisava olhar para a cara de cada deputada e deputado, precisava conferir a austeridade que se implementa pelas forças de um capitalismo neoliberal, cuja primeira plataforma a quebrar é a dos direitos básicos. O debate está, portanto, além do duplo crise econômica e/ou crise política - é a articulação entre ambas que estamos vendo, é a produção de "crises", que são matéria própria do 


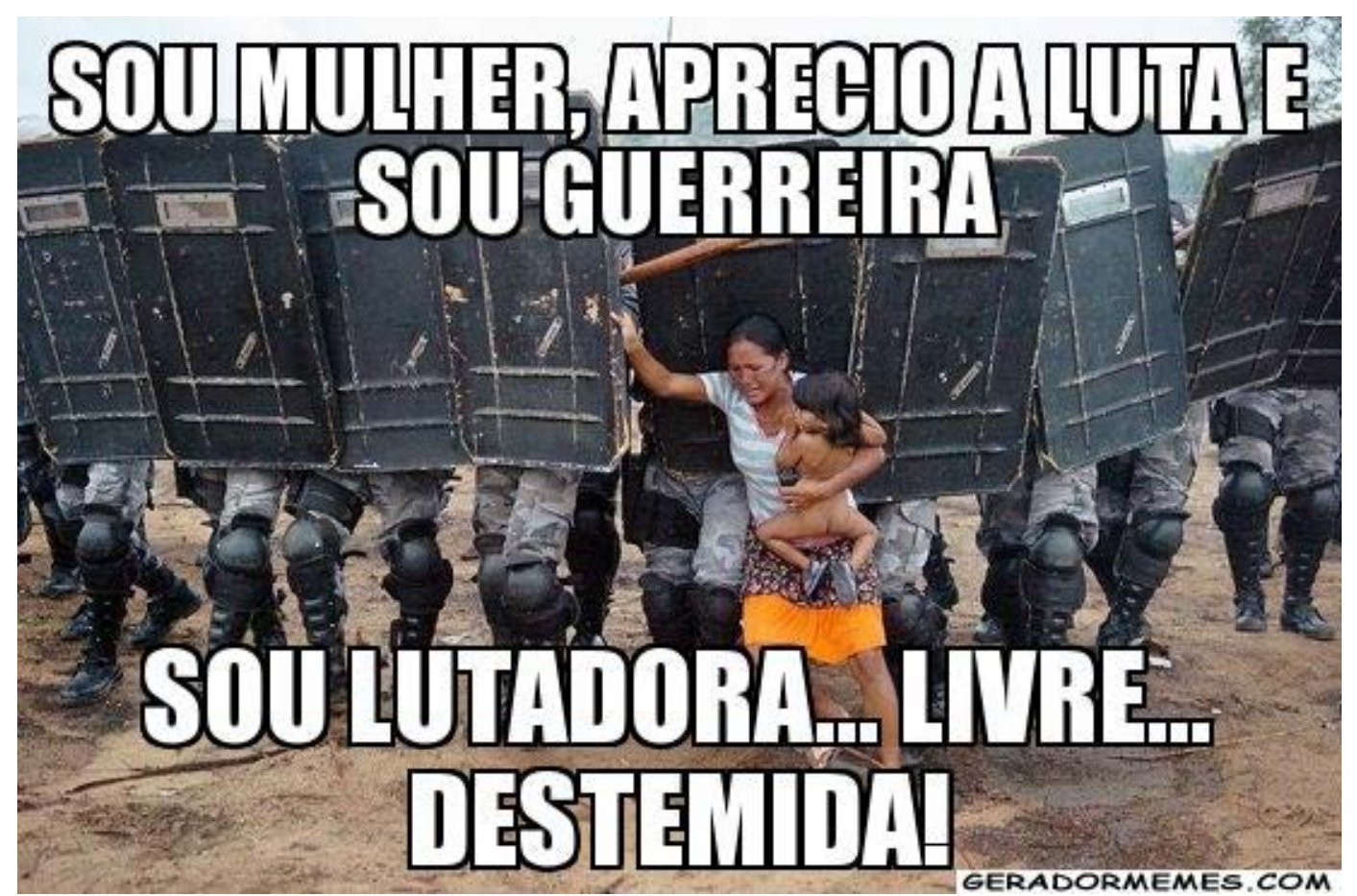

Mulher guerreira e da luta

capitalismo financeiro associado à corrupção dos governos e enriquecimento de atores políticos. 0 que está em jogo são possibilidades de manobra da(s) esquerda(s) no governo, de manutenção de direitos adquiridos e a continuidade da implementação de direitos por vir. Em meio a quebras de contrato, interpretações forçadas de brechas da constituição, "pedaladas" legais assinadas tanto por Dilma como por Temer, e em meio a defesas que não causam nenhum impacto, "Tchau, querida" se tornou a meme daqueles identificados com a destruição verdeamarela do governo de Dilma. Outras posições simpatizantes mas não absortas pelo "contra o golpe" se perguntam se "Tchau!" se refere a Dilma diretamente ou à democracia ela mesma. $\mathrm{O}$ bloqueio do PT para fora do Planalto Central não se concentrou em afastar Dilma, mas, nas mãos do vice Michel Temer, se tornou um redesenho homo-orquestrado que tem excluído e fundido ministérios, entre eles o Ministério das Mulheres, da Igualdade Racial e dos Direitos Humanos - que eu sugeriria chamar de um "golpe ideológico", patriarcal, heteronormativo.

No curso do pró-impeachment e contra o golpe, entre "Tchau!" e "Fica, querida!", nos últimos meses vimos no Brasil a destruição midiática da figura pública de Dilma, uma destruição política, que passa pelo machismo estrutural e pela intolerância que cada vez mais tomam espaço na Câmara e no Senado. Esse machismo estrutural aliado à economia foi nomeado pelas lutas femininas de heterocapitalismo. ${ }^{6} \mathrm{O}$ heterocapitalismo é regra em geral não só da sociedade brasileira, mas o sistema de reprodução social que se sustenta 
no trabalho não pago dos cuidados e trabalhos reprodutivos - pensando os trabalhos reprodutivos e sua relação direta com a reprodução social - ou seja, a maneira como nos "multiplicamos" e somos criados para aderir a um sistema de produção. $\mathrm{O}$ heterocapitalismo se especializa na dominação de um sistema político e econômico em que mulheres, mulheres negras e de cor, negros, indígenas, gays, transexuais, quilombolas, favelados e muitas minorias são diretamente objetificadas e oprimidas, em favor de modos de vida subsumidos à produção, e por isso mesmo normativos e consumistas, e, na maioria dos casos, em crescente débito. ${ }^{7}$ No caso brasileiro, o machismo estrutural se manifesta explícita e desavergonhadamente no discurso de Eduardo Cunha, Jair Bolsonaro, Marcos Feliciano, o próprio Michel Temer e outros tantos deputados. O heterocapitalismo produz a mulher como um imediato do macho produtivo, mulher

Bela, recatada e do lar

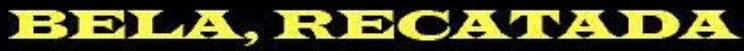 IDO IAUR}

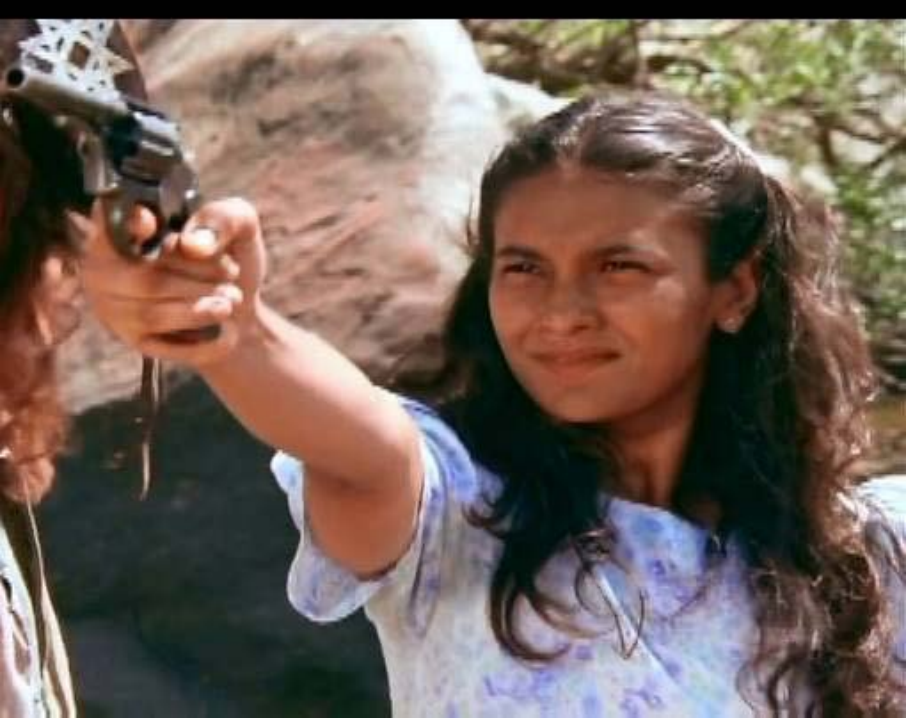

configurada sem direito de voz, de opinião, de luta, de vida pública. Além disso, o heterocapitalismo, na destruição da vida das minorias (ou na redução da vida das minorias à condição de sobrevivência), concebe o racismo como questão já resolvida, em que o silenciamento (à diferença) é apontado como solução das diferenças.

\section{A dimensão pública das lutas, a emergência de novas subjetividades}

Dilma como mulher pública nunca esteve fora do jogo de especulações, julgamentos, acusações. Uma mulher que, eleita presidenta, tem a todo o tempo sua capacidade de governo diminuída por seu gênero: feminino - julgamento que desencadeia outros tantos preconceitos que são associados pelo senso comum à imagem da mulher, entre eles o descontrole, a loucura, a histeria. Dilma também é julgada por sua luta política, desqualificada por sua radicalidade nos anos de resistência à ditadura, cuja história é combatida dentro da Câmara ou do Senado pela nomeação e homenagem a militares que a torturaram. Que relação a destruição de Dilma como mulher pública tem com a vida pública das mulheres, das outras mulheres?

Em meio à reeleição de Dilma em 2014 as ruas ferviam com protestos que acordavam a maioria e o senso comum (afinal, há muito mais do que O Gigante). Os protestos do ciclo que iniciou em 2013 escancaravam nas ruas o posicionamento dos movimentos organizados e de novas constituições políticas com demandas claras. A tomada direta das ruas explicitava o laborioso cotidiano das lutas nas assembleias, nas comunidades, nos grupos de estudo. Uma multiplicação de enunciados surge: desde a tarifa zero, contra os machismos, pelo direito à cidade, a educação como direito, contra a destruição dos ecossistemas e das terras 
indígenas, contra a violência policial e pelo fim da precarização da vida. A resposta negativa de Dilma e do PT para enunciados que criticavam diretamente seu governo foi entre outras a aprovação da lei antiterrorismo, que facilita a criminalização de militantes e de movimentos sociais e a aplicação inúmeras vezes da Lei de Segurança Nacional. As manifestações verde-amarelo que se posicionavam "contra a corrupção", por sua vez, não foram reprimidas. Por quê?

A opressão aos protestos no ciclo 2013-2015, analisada por inúmeras e inúmeros militantes, sociólogas e sociólogos, filósofas e filósofos, foi um sintoma claro do fechamento da máquina do PT-no-governo. A não escuta das ruas e a invenção de inúmeras conspirações para desqualificar o movimento reinauguravam a ruína da relação entre governabilidade e democracia de direitos - que requer, por sua vez, a maior quantidade possível de transversais entre a sociedade e o poder representado, uma questão que não se esgota na noção de "representação", mas que se qualifica na promoção de fluxos, ressonâncias, coemergências. Ao passo que muitos programas sociais foram criados, a vida pública das brasileiras e dos brasileiros já vinha sendo achatada pela condução a um crescimento do país a qualquer custo, um modo de crescimento pautado na precarização das condições de trabalho, endividamento e desenvolvimento industrial destrutivo, tal como o caso da construção de Belo Monte, como o rompimento da barragem de Mariana e a consequente poluição do rio Doce e do mar. E, agora, o que estamos vendo com Michel Temer, o temível presidente interino?

No ciclo 2013-2015 mulheres complexificaram os espaços de protesto, tornando explícitas uma série de demandas e lutas que ficavam sorrateiramente escondidas sob discursos de demandas políticas majoritárias. Entre as lutas das mulheres viu-se uma multiplicação de enunciados e interseccionalidades: muito além de feminismos brancos, são os feminismos negros e os feminismos indígenas que emergem com toda a força, atravessados por manifestações públicas de grupos queer, prostitutas, mães lactantes e libidinosas, transexuais. A luta pela legalização do aborto, contra o feminicídio, e as nuanças e estatísticas que separam aquilo que ameaça mulheres brancas e negras em escalas abissais tomaram o espaço público mais e mais, implementando e diversificando a formação de grupos, de espaços autogeridos e de pedagogias radicais. A produção cultural não fica aquém. Ela insurge dos corpos, e se torna motor da luta. O privilégio branco se torna evidentemente sujeito de debate. Como então relacionar a vida pública de Dilma (e a perda de seu direito de governar) à vida pública das mulheres, das outras mulheres, que já estavam "lá" no ciclo de manifestações, nas Marchas das Vadias, nas Paradas Gay, na luta pela legalização do aborto? Como resistir na defesa da democracia de direito sem conciliar achatando sob um significante ("luta pela democracia") a singularidade das lutas que já se faziam públicas a partir do ciclo de 2013?

Pois bem, o que se vê na escala da macropolítica na condução do processo do impeachment e no governo interino de Temer é exatamente a conexão entre a emergência das minorias com o apagamento político de Dilma. O seguimento do processo de impeachment de Dilma enumera causas inconsistentes, contestadas por deputados, promotores, advogados, entre muitos. O processo de impeachment arrasta consigo as vidas das outras mulheres e das minorias, entre as que emergiram como subjetividades possíveis pelas lutas e pelas políticas de distribuição de renda. O impeachment associa uma inabilidade referida a Dilma de governar (por ser mulher, por seu histórico de luta à 
esquerda) ao achatamento de modos de vida que, na perspectiva heteropatriarcal, não deveriam adquirir autonomia. A emergência de novos modos de vida, por direitos adquiridos, pela instalação iniciática de um estado de bem-estar social não é desejada por aqueles que operam esse "golpe ideológico" - fato comprovado na fala dos deputados heteronormativos e fascistoides no andamento das votações para o seguimento do impeachment no Congresso Nacional. Tais atores da macropolítica não economizam afirmações de que fazem parte de um extrato privilegiado da sociedade, reproduzindo binarismos crassos, tais como poder do opressor sobre o oprimido!

\section{Nós, dondocas? \#Sóquenão}

Uma matéria na revista Veja sobre Marcela Temer, a mulher do vice Michel Temer, com o enunciado de "bela, recatada e do lar" foi lançada no dia seguinte ao da votação na Câmara pelo seguimento do processo de impeachment (junho 2016). A matéria foi suficiente para expor a mentalidade machista que se apresentou na condução do processo de impeachment. O binarismo com o qual o heterocapitalismo rege a vida da mulher ali estava explícito: a orientação da mulher à vida do lar, e a política como "assunto de homens"; ao que "mulheres públicas" responderam prontamente reclamando seu direito de expressar-se e de ocupar a esfera pública. A mulher cuja vida é "apenas do lar" é tão somente a dondoca, esposa do político corrupto. Há, entretanto, outros binarismos para serem quebrados: (a) os trabalhos domésticos e de cuidado feito por mulheres negras e de cor, trabalhos que por sua vez sustentam a vida pública das mulheres que têm o privilégio de ter vida pública; e (b) a vida das mulheres negras, de cor e indígenas, sujeitas à opressão de muitas ordens, cujas vidas não foram representadas na hegemonia branca agrupada pela resistência à "bela, recatada, e do lar", mas sim no "bela, guerreira e da luta" (e infinitas variações). Mulheres negras e trans se posicionaram em contraposição a esse enunciado, trazendo no seu lugar imagens de pessoas que lutam, de mulheres brancas e não brancas cujas vidas são ameaçadas nas diversas formas de machismo e feminicídio que diariamente as molesta e oprime.

No heterocapitalismo, os enunciados do mundo patriarcal replicam a realidade das mulheres atreladas à vida privada, em que a sexualidade das mulheres é todo o tempo equiparada a uma escala de modos e valores dos homens - o que chamo de modos de semiotização do modo de vida das mulheres determinados pelos homens. Esses modos machistas, patriarcais, heteronormativos, escondem por sua vez diversos modos de semiotização que incluem submissão, violência, sexualização e evidentemente trabalho precarizado e não remunerado.

Quem viu a imagem de uma mulher sem consciência após uma bomba de gás em Brasília no dia da votação do impeachment no Senado? Ela estava com cerca de 20 anos, viera do Nordeste e fazia parte do protesto contra a votação do impeachment. A imagem de Marcela Temer (no "bela, recatada e do lar"), por sua vez, foi produzida para funcionar como uma espécie de espelho que pretende operar como um espelho binário, engolindo as mulheres na sua diversidade. Ela deixa evidente que o machismo não é coisa apenas de homens, mas também daquelas mulheres que lutam contra o feminismo, e das mulheres protagonistas do "feminismo" que sujeita a mulher ao modo da vida pública semiotizada por homens. Naquela lógica do espelho, a vida pública de uma mulher que luta não é possível. "Do outro lado" do espelho da dondoca cosmetizada há, contudo, 


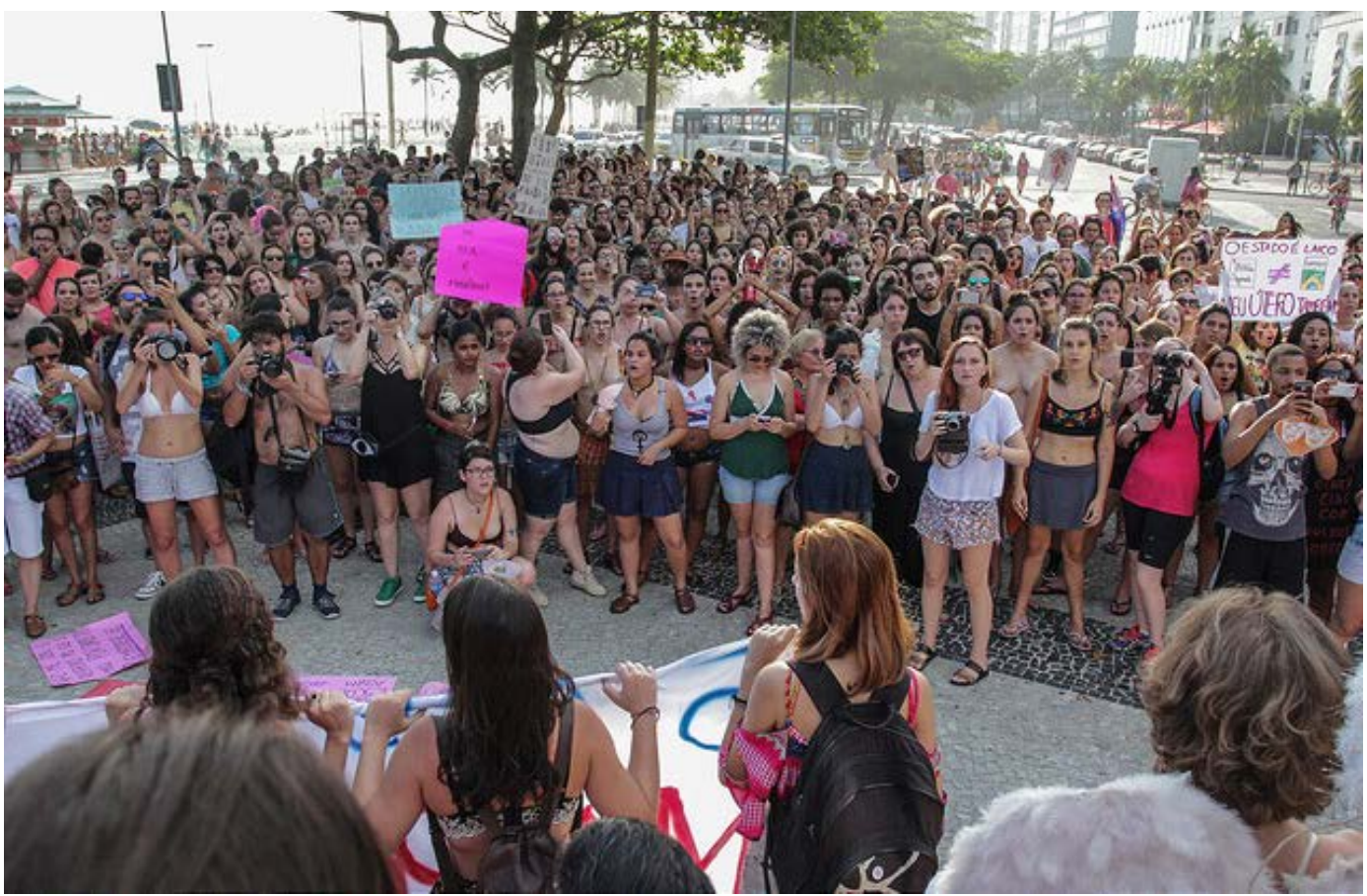

Marcha das Vadias, Rio de Janeiro, 2015

uma variação incontrolável de mulheres e minorias que lutam, que à sua maneira sustentam um país, no trabalho, nas universidades, nas escolas, nas casas, nas lutas sociais. A vida persevera ainda que oprimida, ainda que o fôlego seja roubado a cada dia. ${ }^{8}$

\section{Análises, análises, análises}

Se reclamo a imagem e a força de Dilma como mulher agora - e ao mesmo tempo estendo a significação feminina para as subjetividades que emergem e para a democracia ela mesma -, é para compor com as resistências que se levantam - resistências de diversas ordens, não apenas que se aliam diretamente à defesa das mulheres ou do partido das trabalhadoras, ou dos partidos dos outros trabalhadores - não incluídos na problemática identidade partidária que o PT replica.
Hoje vemos que a luta pela vida pública de uma mulher afastada de seu poder de governar (Dilma) não para nesse feito, pois afunda o exercício da democracia e achata as subjetividades emergentes em seus processos de luta. Como disse acima, a força que tirou Dilma destrói paulatinamente os direitos constitucionais (educação, saúde, previdência...) e os direitos adquiridos (Bolsa Família como ícone e um sem número de benefícios ${ }^{9}$ ). As forças fascistoides que tomam o Planalto Central, roubando o lugar de protagonistas centrais, literalmente, não economizam quanto a oprimir aqueles corpos que se distinguem na multidão que protesta, não economizam quanto a oprimir aqueles corpos e modos de vida que fogem da normalidade binarista e da servidão ao trabalho como o primeiro ponto para a civilidade de direitos. E censuram, e tolhem, e julgam. 
O desafio que aquelas e aqueles que não abrem mão de falar a partir de sua singularidade em devir de resistência, daquelas e daqueles que não se identificam no binarismo do pró e contra o golpe, e que não se aquietam sob a defesa de "Volta, querida!" - pedindo a volta de Dilma -, tem sido buscar entender se é necessário produzir uma demanda comum. Por hora a luta pela democracia pode ser o ponto onde se concentra a força que faz perseverar movimentos, mas a democracia depende constantemente das radicalizações que a constituem... Li no livro Undercommons que "adquirir 'governabilidade' é colocar a democracia a trabalhar. (...) A governabilidade é sempre gerada, sempre orgânica a uma situação. A democracia [por sua vez] não se encaixa em muitas situações, e deve ser trabalhada (...)" ${ }^{10}$ Não teria sido a "governabilidade" aquilo que o PT perdeu nos últimos anos? Diante da afirmação do cotrabalho entre democracia e governabilidade, pensando na singularidade dos movimentos que já estão em curso, vou contra a conspiração que achata os sonhos de que diante de um preâmbulo de uma crise econômico-política ainda maior ainda não conseguimos definir a "pauta do dia". Basta um olhar não histérico, porém, talvez, um pouco histriônico para o dia a dia das lutas. Basta encontrar mais pontos de análise do que \#ForaTemer e "volta, democracia".

Duas perguntas para complexificar esta análise: (a) diante das representações da política no planalto central que articula a dualidade impeachment/ golpe, será que os movimentos, na escuta de suas singularidades, se fortalecem sob o enunciado comum da defesa da democracia? (b) na relação democracia/governabilidade não seria o chamado de eleições gerais o ponto de concentração temporal, contingente das lutas pela democracia, mas também a própria insistência na produção da democracia de fato - a reprodução das lutas sociais de base!? Ou seja, a proliferação dos modos expressivos, de organização e de existência.

\section{Singularidades em luta}

Para que servem enunciados, imagens, memes quando circulam? Para desprogramar o dito que se afirma como verdade. Para desmascarar o óbvio (a objetividade da macropolítica e do heterocapitalismo na sua relação com a corrupção econômica, com o corporativismo, com a meritocracia) e trazer dispositivos que disturbem. Mas como é que a replicação desses enunciados, nessa semiótica incontrolável, interfere na normalidade heteronormativa e machista que vemos replicada não só na mídia, cada vez mais assustadoramente no discurso dos "nossos" deputados, senadores, interinos, ministros, mas dos nossos primos, vizinhos, amigos...? As redes sociais e seus memes operam muitos endogenismos - o fato de que na maioria das vezes falamos entre nós mesmas e mesmos. Como modular esse trabalho semiótico para que não corrobore ainda mais a reterritorialização do outro a partir de suas formas já concretas (antifeminazi, antiesquerdistas, antisocialistas, antitransgeneristas, antibolsista, anticotista...); e para que não opere, portanto, na continuidade da reprodução endogênica dos enunciados, de pouco ou quase nulo efeito de contágio e transformador?

O heteronormativismo gera apenas duplos, duplos negativos de uma vida pública, duplos que são opostos: vida do trabalho e vida do lar. A vida pública, gerida na dobra democracia/governabilidade, fica a cargo dos privilegiados corruptos e meritocratas - todos homens. Nos modos normativistas, sem dúvida, a vida é controlada e cosmetizada, e se move cada vez mais longe da potência da própria vida (potência de criar e diferir). 

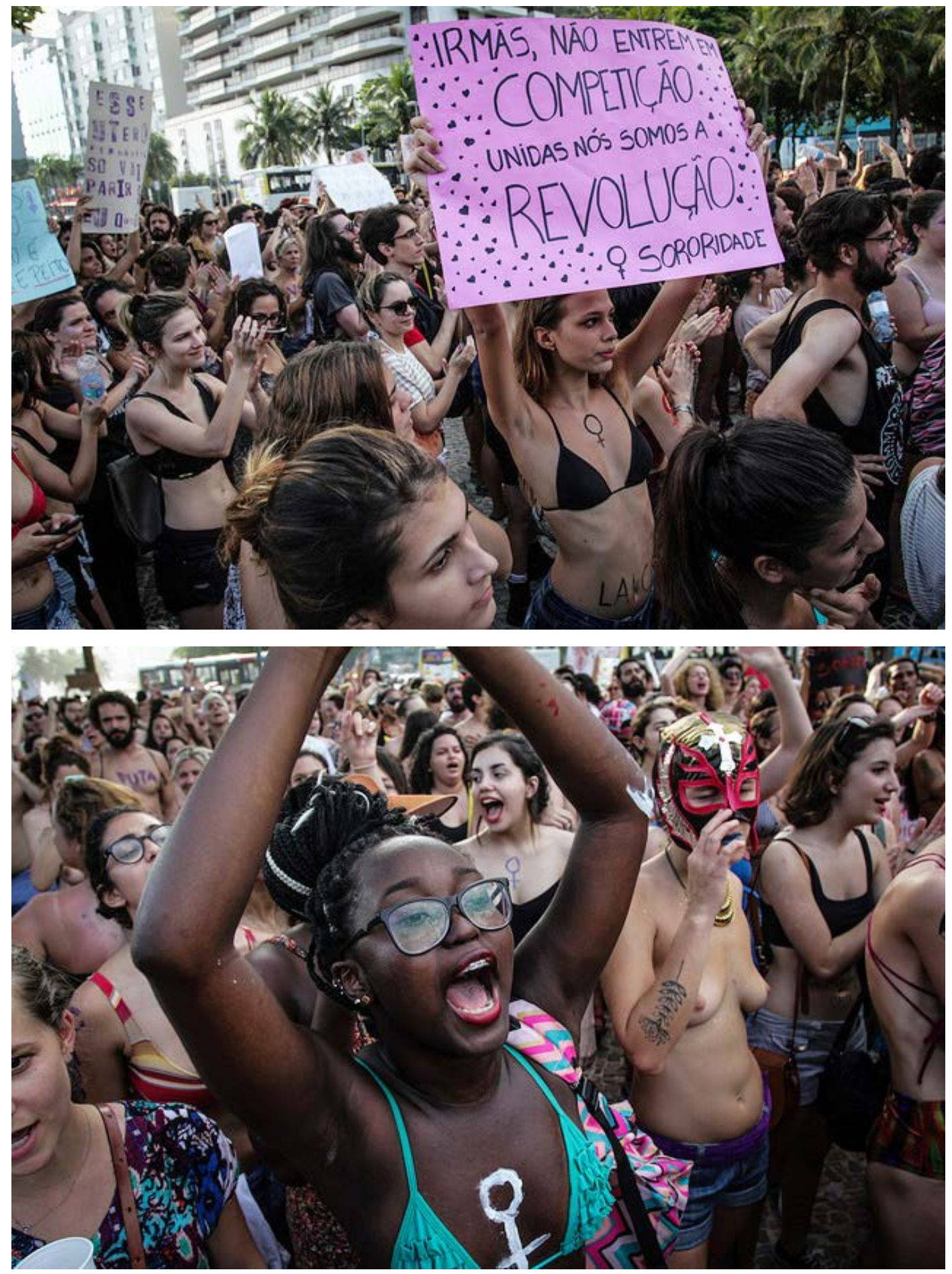

Marcha das Vadias, Rio de Janeiro, 2015 

Nos modos normativistas a vida se torna potência de expressão de semióticas pré-codificadas. Não há imagem mais intolerável para o heternormativismo do que a das mulheres com seus peitos de fora, amamentando, vadias, lúcidas e luxuriosas; não há imagem mais radical que as transgêneres diante do espelho binário heteronormativo. Essas vidas são, por sua vez, semiotizadas pelo desejo, mas não pelo desejo de poder identificado ao capital patriarcal, corrupto, corporativista e meritocrático.

A dimensão pública da vida de uma mulher só pode ser a dimensão que acolhe e que desgarra a luta. A produção da própria diferença. A dimensão pública da vida de uma mulher é o embate direto ao machismo estrutural, ao racismo e também ao heterocapitalismo que tenta destruir os direitos das minorias. A luta das mulheres vai além da luta pela democracia, uma luta que não se esgota em demandar, em replicar enunciados, mas gerar condições para a própria vida, construindo diversos comuns além do binarismo público/privado. Não é à toa que vários movimentos falam há décadas do "comum das lutas". A singularidade das lutas, por isso, vai contra o aparelhamento que sofrem vários movimentos, entre eles, a sobrecodificação da "luta pela democracia" como eco de governismo PTista. A singularidade das lutas, que está além da luta pela democracia, é aquela que não deixa esquecer a constante dobra entre o indivíduo e suas formas coletivas, em que o subjetivo e o político fazem parte da mesma matéria, o subjetivo e o objetivo da vida e das lutas.

O que a democracia/governabilidade pode aprender da singularidade das lutas, do modo de lutar das mulheres e das minorias, é a ética de proteção à vida, o que merge (mistura, promiscui) a democracia com correntes do feminismo antifascista e contraheterocapitalista propriamente dito. Portanto, a democracia/governabilidade não se torna possível apenas quando fomenta um "estado educador", implementando e apoiando pedagogias diversas, auto-organizadas, de proliferação de sentidos e de semióticas a partir de uma ética de variação da vida, mas quando há uma permeabilidade mínima com o poder representado, aquele cotrabalho democracia-governabilidade. Se a democracia garante a vida, ela deve ser defendida. Mas se aqueles que estão em poder das transversais que estendem o governo à democracia operam em favor de interesses corruptos, corporativistas, fascistoides e meritocráticos, heteronormativos, seu poder deve ser destituído. A democracia no atrito com a governabilidade, como espaço de gestão e cuidado da vida só é possível se se pode garantir a tomada de voz e de corpo a partir das diversas singularidades que nos constituem.

A democracia, como mulher pública e que luta, é efetiva quando acompanha os percursos éticos das mulheres, das mulheres de cor, negras, indígenas, das minorias, das crianças, das velhas e dos velhos, dos homens, das estudantes e dos estudantes, das grevistas e dos grevistas, das trabalhadoras e dos trabalhadores, para além da dicotomia público e privado e dos modos heteronormativistas que semiotizam, oprimem e isolam nossos corpos. É preciso seguir o movimento em direção às lutas comuns, mas preservar a singularidade, para que possamos lutar sim pela defesa das mulheres na vida pública (o cumprimento de seus mandatos) e também para que possamos lutar "para além" da vida pública da democracia.

\section{NOTAS}

1 Haraway, Donna. Ciencia, cyborgs y mujeres. La reinvención de la naturaleza. Madrid: Ediciones Cátedra, 1995. 
2 Rolnik, Suely. Cartografia sentimental: transformações contemporâneas do desejo. Porto Alegre: Sulina/Editora da UFRGS, 2011.

3 Preciado, Paul. Cartografias queer: o flâneur perverso, a lésbica topofóbica e a puta multicartográfica, ou como fazer uma cartografia "zorra" com Annie Sprinkle. Performatus/Inhumas, ano 5, n. 17, jan. 2017.

4 Butler, Judith. Gender trouble: feminism and the subversion of identity. New York/London: Routledge, 1990.

5 O embate macropolítico que se expressa em âmbito federal gera diversos efeitos locais. A ditadura que nunca acabou escuto das favelas do Rio de Janeiro; portanto, não deixo passar a relação entre a esfera macropolítica e as pontuais lutas de minorias e as locais. Populações historicamente oprimidas têm colocado "antes" da demanda pela resolução do pró ou contra o golpe a demanda pelo fim da repressão policial, substituindo o "Primeiramente \#ForaTemer" por "Primeiramente \#ForaUPP". Como exemplo, o movimento \#FomedeViver, organizado recentemente no Rio de Janeiro.

6 Referências para leitura são Amaya Perez Orozco, Subversión feminista de la economia: aportes para un debate sobre el conflicto capital-vida. Madrid: Traficantes de Sueños, 2014; e Silvia Federici, El caliban y la bruja, mujeres, cuerpo y acumulación originaria. Madrid: Traficantes de Sueños, 2010.

7 Sobre a relação entre capitalismo financeiro e débito, ver Maurizio Lazzarato, O governo do homem endividado. São Paulo: N-1 edições, 2017.

$8 \mathrm{Eu}$, como mulher, branca, como militante, como acadêmica, como mãe de uma menina, como pessoa que anda em busca e ou em defesa da democracia, tenho cultivado um olhar para a vida das mulheres que mais e mais perturbam a "vida da normalidade", a vida heteronormativa. Cavando dentro de mim o privilégio branco ainda não muito analisado, tenho aprendido que as militâncias feministas não brancas e não transfóbicas são essas que transformam pelas ações, pela proliferação de sentidos de ser mulher, mãe, trabalhadora, militante, pelo fazer política e preservando uma ética de preservação da vida contra o capital.

9 Programas de distribuição de renda, criados ou mantidos pelo governo de Dilma: Bolsa Família, Bolsa Atleta, Bolsa Escola, Bolsa Estiagem, Bolsa Permanência (PBP), Bolsa Creche, Bolsa Verde, entre outras.

10 Stefano Harney; Fred Moten. The Undercommons. Colchester/New York/Port Watson: Autonomedia/ Minor Compositions, 2013.

Cristina Thorstenberg Ribas é doutora (PhD) pelo Departamento de Artes no Goldsmiths College University of London (2017), mestre pelo Instituto de Artes da Uerj (2008) e graduada pelo Instituto de Artes da UFRGS, Porto Alegre (2004). Bolsista PNPD (pós-doutorado) pela Capes no PPGAV do Instituto de Artes da UFRGS. Trabalha como artista, pesquisadora e eventualmente como curadora. Tem experiência na concepção de projetos operando passagens entre a estética e a política, na forma de residência artística, pesquisa militante e pedagogia radical. Em 2011 criou a plataforma on line Desarquivo.org para hospedar sua pesquisa sobre práticas artísticas e articulações políticas a partir do Arquivo de emergência (2005). Realizou junto a muitos autores o projeto Vocabulário político para processos estéticos. Faz parte da rede de pesquisadores Conceptualismos del Sur.

P. I 12-I 13: Marcha das Vadias, Rio de Janeiro, 2015 